This item was submitted to Loughborough's Research Repository by the author.

Items in Figshare are protected by copyright, with all rights reserved, unless otherwise indicated.

\title{
Optimising I-V measurements of high capacitance modules using dark impedance measurements
}

\section{PLEASE CITE THE PUBLISHED VERSION}

http://dx.doi.org/10.1109/PVSC.2016.7750366

PUBLISHER

(C) IEEE

VERSION

AM (Accepted Manuscript)

LICENCE

CC BY-NC-ND 4.0

\section{REPOSITORY RECORD}

Eeles, Alexander, Ralph Gottschalg, and Thomas R. Betts. 2019. “Optimising I-V Measurements of High Capacitance Modules Using Dark Impedance Measurements”. figshare. https://hdl.handle.net/2134/24051. 


\title{
Optimising I-V measurements of high capacitance modules using dark impedance measurements
}

\author{
A.S. Eeles, R. Gottschalg, T.R. Betts \\ Centre for Renewable Energy System Technology (CREST), Loughborough University, Leicestershire LE11 $3 T$ TU. \\ Email of corresponding author: A.Eeles@lboro.ac.uk
}

\begin{abstract}
A method is demonstrated to optimise pulsed IV measurements of high capacitance PV modules, using dark IV and impedance measurements. The impact of capacitance during $\mathrm{I}-\mathrm{V}$ measurements is minimised by changing the shape of the voltage ramp. The optimisation can be performed simply and automatically for each individual module during the charging period for the simulator. As an additional benefit of this method the extracted $C-V$ profile can be used to estimate the minority carrier lifetime for the module. The system is demonstrated by using a high capacitance $n$ type module, which is successfully measured in a single $10 \mathrm{~ms}$ illumination pulse.
\end{abstract}

Index terms - High capacitance, high efficiency, I-V, C-V, performance measurement, pulsed simulator, carrier lifetime.

\section{INTRODUCTION}

It is well known that high efficiency photovoltaic modules usually exhibit large internal capacitance and that this can cause errors in the measured power output if the voltage is changed too quickly during a measurement [1]. This causes the measurement time required to measure high efficiency modules to be much longer than for the technologies of the last decades.

The problematic capacitance originates from the charge stored by minority carriers in the quasi neutral region. The size of this capacitance is proportional to the minority carrier lifetime, because, the higher the lifetime, the more carriers will accumulate at a given voltage, and the more charge will be stored. This explains why the capacitance is found to be higher in high efficiency modules. As efficiencies continue to increase in the future high module capacitance is likely to become more and more of a problem for performance measurements.

Common tactics for measuring high capacitance modules are either using speciality long pulse length simulators with a stabilised illumination of $100 \mathrm{~ms}$ or more, or splitting the measurement up into multiple sections / points which can be measured in separate illumination pulses, known as the multi flash or multi point measurements [2]-[5]. A simple solution is to measure only the region around the maximum power point [6]. This solution is adequate in some cases if only the maximum power point is needed and the maximum power point voltage is already approximately known before the measurement. It is also possible to reduce the required measurement time by reducing the number of measurement points [7]. This becomes a trade off with increased errors due to interpolation between points.

The simple approaches make inefficient use of time and lamp life. By intelligently designing the voltage measurement profile it is possible to make full $\mathrm{I}-\mathrm{V}$ measurements without the need for long pulse durations, negating the need for specialist simulators or using multiple pulses.

The capacitive charging current in a PV device is dependent on the capacitance and also the conductance, both of which vary strongly with voltage. By using non-linear voltage ramps it is possible to significantly reduce the measurement time because some regions of the I-V curve can be measured more quickly allowing more time for the other regions. Other methods to do this have proved successful [8]-[9], but the method presented here represents a significant improvement in the setup of the optimum voltage ramp because it can be performed quickly, automatically and individually for each module without the need for extra illumination pulses. If the voltage ramp is not designed individually for each module then variation in a production run can cause problems for the measurement system.

Dark impedance measurements are used to determine the capacitance. Impedance measurements are a more direct method to measure the capacitance than open circuit voltage decay which requires more modelling and assumptions [10][11]. Another possibility is the photocurrent response method [8]. In comparison to that the main advantage of impedance is that no extra illumination pulses are necessary making it practical to obtain individually $\mathrm{C}-\mathrm{V}$ measurements for every module. In a production line environment these measurements could be made immediately before the I-V measurement in the period while solar simulator is charging, before the next illumination pulse. This way the voltage profile for the I-V measurement can be optimised for each module.

The $\mathrm{C}-\mathrm{V}$ and dark I-V measurements produced during this method are highly useful in their own right. From the high voltage region of the $\mathrm{C}-\mathrm{V}$ curve minority carrier lifetime can be extracted [12], and if information is known about surface enhancement factor from the texturing of the cells then the base doping density can be determined from the low voltage region [13]. These parameters would provide an extra quality control check and having a history of these measurements would be a powerful tool in helping to diagnose unintentional 
process drift on a production line. This additional information is another significant advantage of using this method.

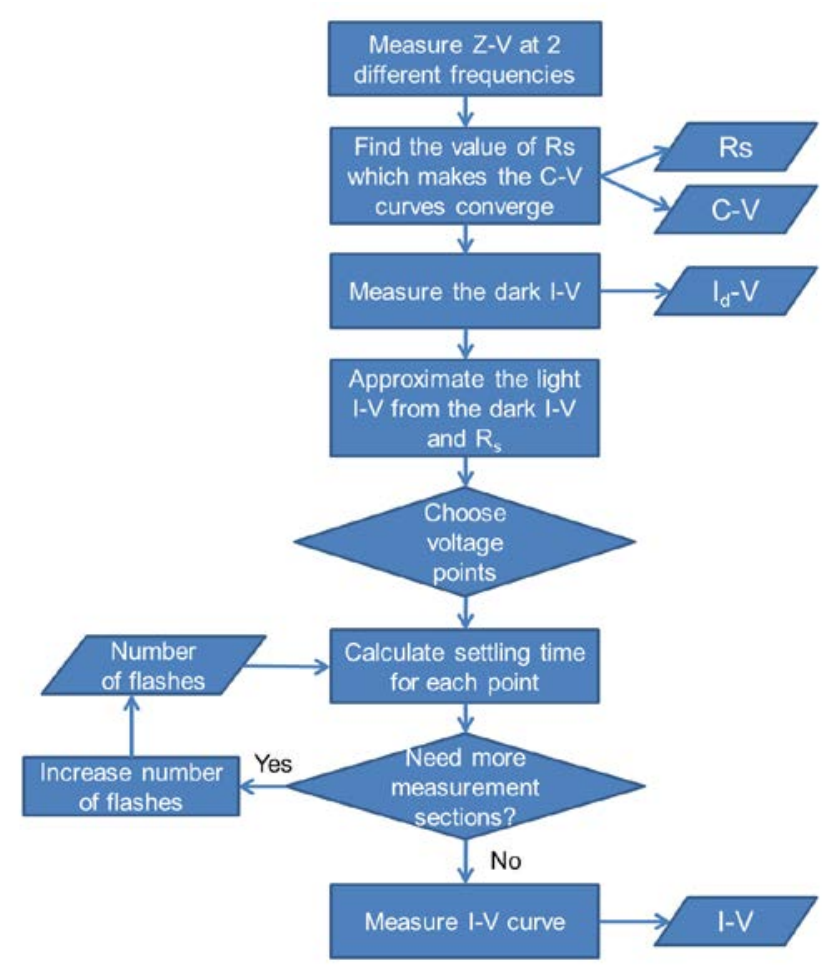

Fig 1. Schematic for the I-V curve measurement

\section{METHOD}

Fig 1 shows a flow diagram for the optimisation procedure. The essence of the method is that the dynamic response of the module can be only be calculated from full knowledge of the capacitance $(\mathrm{C}-\mathrm{V})$ and the steady state light $\mathrm{I}-\mathrm{V}$ curve. However since the light I-V curve cannot be known before the measurement it is estimated from the dark I-V curve. The $\mathrm{C}-\mathrm{V}$ curve is measured directly using impedance measurements. The knowledge of the dynamic response is then used to minimise the capacitive charging errors.

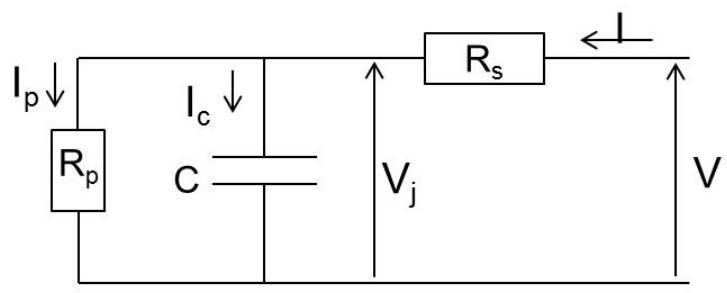

Fig 2. Equivalent circuit diagram for small oscillations or voltage steps. Note that the voltages and currents represent the voltage changes form the steady state value not absoulte values.
First of all, impedance $(\mathrm{Z})$ measurements are performed at two different frequencies which allow the series resistance and the $\mathrm{C}-\mathrm{V}$ characteristic of the module to be extracted. Fig 2 shows an equivalent circuit diagram for a PV module which can be used for small voltage oscillations as is the case for impedance measurements. The equivalent circuit will also be used for modelling the small voltage steps made during the I$\mathrm{V}$ curve sweep. Often in $\mathrm{C}-\mathrm{V}$ measurement the series resistance in the device model is omitted. At the high forward bias required it is very important to include the series resistance element. This makes it necessary to measure the impedance at two different frequencies in order to calculate all the elements.

TABLE I

MEASUREMENT POINTS USED IN EACH SECTION OF THE I-V CURVE FOR THE DEMONSTRATION MEASUREMENT.

\begin{tabular}{|l|c|}
\hline Section & Measurement points \\
\hline$-1 \mathrm{~V}$ to $2 \mathrm{~V}$ & 4 \\
\hline $2 \mathrm{~V}$ to $0.95 \mathrm{~V}_{\mathrm{mpp}}$ & 6 \\
\hline 0.95 to $1.05 \mathrm{~V}_{\mathrm{mpp}}$ & 20 \\
\hline $1.05 \mathrm{~V}_{\text {mpp }}$ to $0.97 \mathrm{~V}_{\text {oc }}$ & 4 \\
\hline $0.97 \mathrm{~V}_{\text {oc }}$ to $1.03 \mathrm{~V}_{\text {oc }}$ & 6 \\
\hline
\end{tabular}

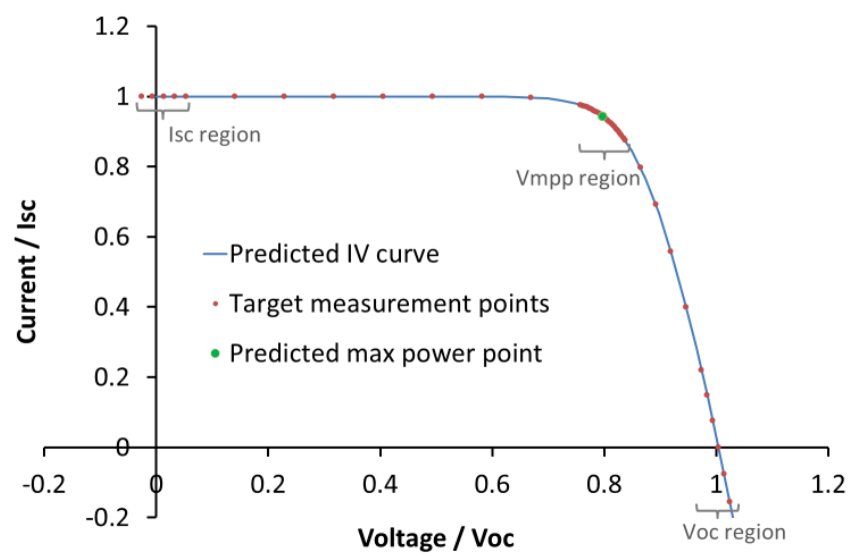

Fig 3. The target voltage measurement points distributed on the estimated I-V curve.

From the dark $\mathrm{I}-\mathrm{V}$, the series resistance and an expected value for $I_{\mathrm{sc}}$ an approximation of the light $\mathrm{I}-\mathrm{V}$ curve can be made. This estimation of the light $\mathrm{I}-\mathrm{V}$ curve is necessary at several points in the creation of the voltage sweep. In order to further reduce the required measurement time the measurement point density is reduced outside of the areas of interest. The positions of interest are $\mathrm{V}=0, \mathrm{~V}_{\mathrm{mpp}}$ and $\mathrm{V}_{\mathrm{oc}}$. These points are estimated from the I-V curve approximation. The number of points in each section can be varied. The numbers used in this demonstration are shown in Table I and displayed graphically in Fig 3. Once the points are set then the charging current after the step is modelled from considering the equivalent circuit in Fig 2. 


$$
I=A \exp \left(-\frac{t}{\tau}\right)+I_{\text {fin }}
$$

Where the factor $\mathrm{A}$ is given by

$$
A=\frac{\Delta V R_{p}}{R_{s}\left(R_{s}+R_{p}\right)}
$$

The decay time constant is given by

$$
\tau=\frac{C R_{s}}{1+R_{s} / R_{p}}
$$

$I_{\text {fin }}$ is the final settled current and $\Delta V$ is the size of the voltage step. The values of $C, R_{s}$ and $R_{p}$ found from the impedance measurements. As measured they are a function of the voltage from the dark measurement. They require converting to a function of the voltage when under illumination. The difference is due to the reversal of the current across $\mathrm{R}_{\mathrm{s}}$ in the two instances. In order to make this conversion the estimation of the light I-V curve is used.

Next the settling time for each step is calculated so that the error for each measurement point is equal. The error for each point is defined as the distance between the normalised versions of the measured and the steady state I-V curves in the direction perpendicular to the steady state curve. By design the error will be small, so using Fig 4 the error can be expressed simply as a function of the current error and the gradient of the I-V curve.

$$
\varepsilon_{i} \approx I_{e r r, i}\left(\left(\frac{d I}{d V}\right)_{i}^{2}\left(\frac{V_{o c}}{I_{s c}}\right)^{2}+1\right)^{-1 / 2}
$$

Finally if the predicted error is within an acceptable range the I-V measurement is made. If the predicted error is too large either the number of measurement points can be reduced or the number of illumination pulses can be increased

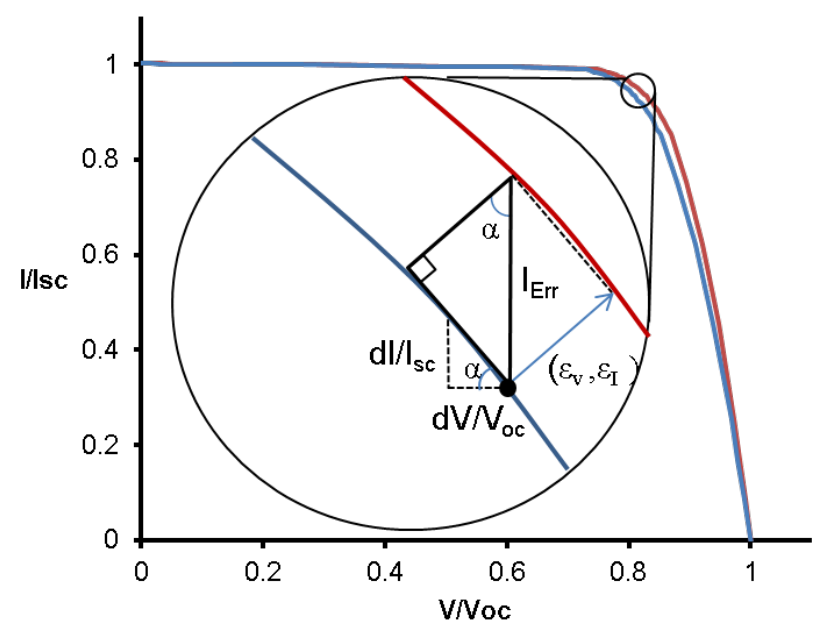

Fig 4. Diagram showing the definition of the error and how the error can be approximated by equation 4 .
As further information the minority carrier $\left(\tau_{m}\right)$ lifetime and doping density can be calculated from the $\mathrm{C}-\mathrm{V}$ curve. The minority carrier lifetime is calculated from the higher voltage region where the build-up of minority carriers in the bulk (diffusion capacitance) is the dominant charge storage mechanism. In this region the diffusion capacitance is exponentially dependent on the voltage and it can be shown that [14]

$$
\tau_{m}=\frac{C}{d I / d V_{j}}
$$

The doping density can be extracted from the lower voltage region of the $\mathrm{C}-\mathrm{V}$ curve where the change in width of the space charge region (junction capacitance) dominates. This doping density measurement requires also knowledge about the texturing of the device, since this will increase the area of the junction relative to the cell cross section [13]. In the demonstration presented in this paper this information was not known so the doping density was not calculated.

\section{RESULTS \& DISCUSSION}

The value of the series resistance which made the two $\mathrm{C}-\mathrm{V}$ curves converge was $0.3 \Omega$. The resulting $\mathrm{C}-\mathrm{V}$ curve for the $\mathrm{n}$ type module is shown in Fig 5. The capacitance per cell is displayed as function of the junction voltage per cell. The two regions where the capacitance is dominated by different charge storage mechanism can clearly be seen. At voltages below $0.4 \mathrm{~V}$ the junction capacitance dominates and overall the capacitance is low. At increasing voltages the diffusion capacitance dominates and causes the capacitance to increases exponentially. In the high voltage region the measured capacitance agrees very well with the theory. The extracted base minority carrier lifetime is $70 \mu s$.

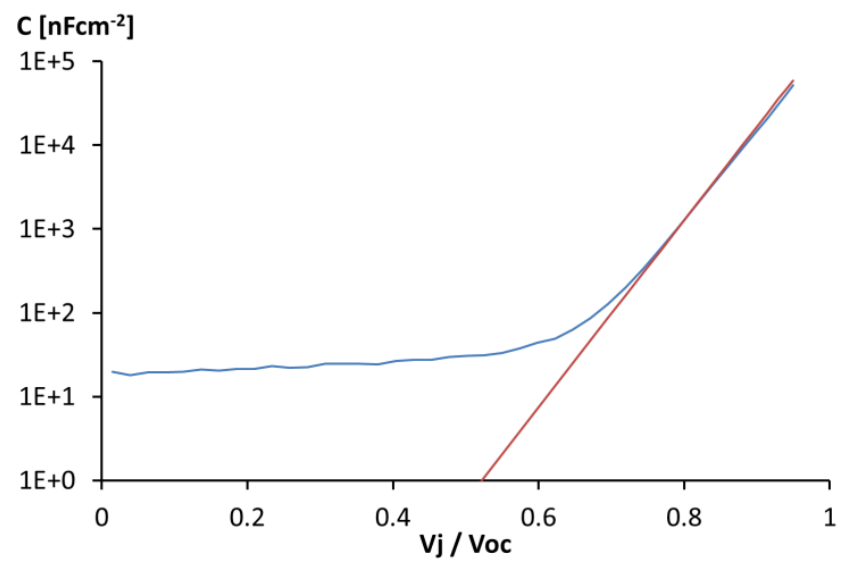

Fig 5. Measured capacitance of the $\mathrm{n}$ type module along with exponential fit for the capacitance. 


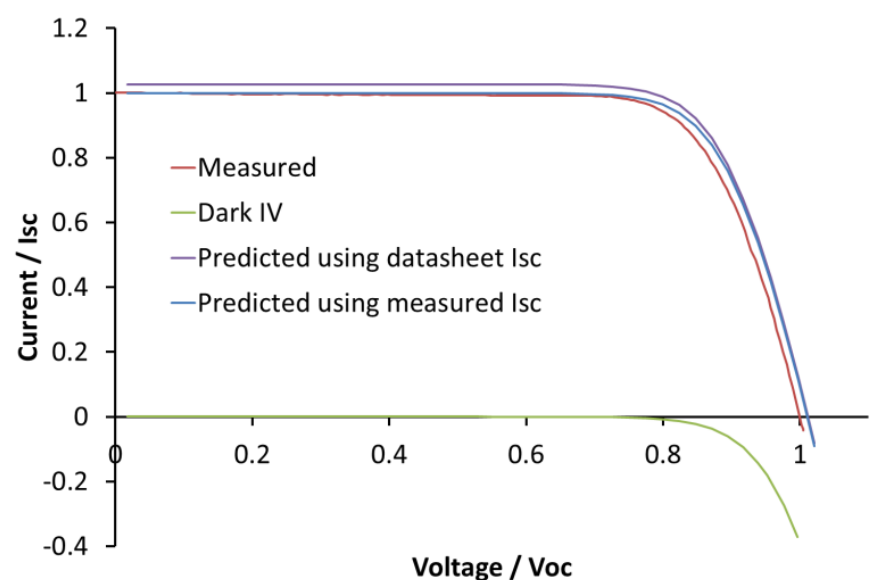

Fig 6. Estimation of the Light I-V curve from the dark I-V curve.

The comparison of the estimated, measured and dark IV curve can be seen in Fig 6. In the figure, two different light I$\mathrm{V}$ curve estimates are shown. The difference is the $\mathrm{I}_{\mathrm{sc}}$ values used, which are either the datasheet value or the value measured under illumination. The I-V curve as measured in the light is also shown for comparison. In this case there is a $2.7 \%$ difference between the datasheet and measured values of $\mathrm{I}_{\mathrm{sc}}$, which obviously propagates to the estimated curves. In the case of using the measured $\mathrm{I}_{\mathrm{sc}}$ value, a better match to the measured I-V curve overall is achieved, however a small discrepancy remains in the $\mathrm{V}_{\mathrm{oc}}$. This example serves as a good demonstration of why it is important to make an actual measurement of the light $\mathrm{I}-\mathrm{V}$ curve for final performance assessment, rather than trying to reconstruct it from the dark I$\mathrm{V}$ curve and a measured Isc. The remainder of the analysis in this example continues using the curve estimated from the datasheet value to show that the method works even in this case.

An example of the voltage ramp created for the measurement is shown in Fig 7. Also shown is the measured current as a function of time. The example shown is for a back contact module, it is similar to the case of the $\mathrm{n}$ type module but the behaviour of the current as a function of time is more pronounced. Each time the voltage is stepped there is a large downward spike in the current which then decays back to the steady state value.
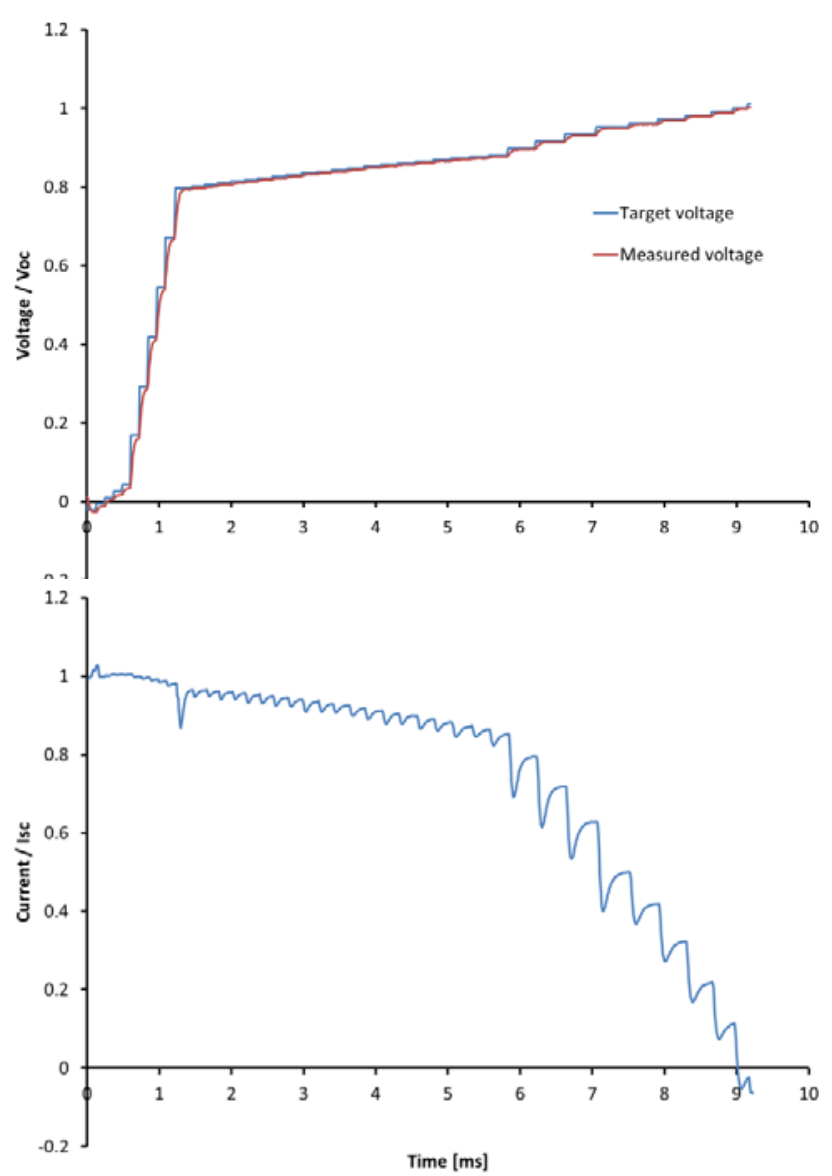

Fig 7. Voltage and current as a function of time during the illumination pulse. Both the target and the actual measured voltage are shown.

Using the multi-flash method eight 10ms illumination pulses were needed in order to get the forward and reverse I-V curves to converge. The predicted error using the new method to measure the I-V curve in one $10 \mathrm{~ms}$ pulse was $0.03 \%$, which is significantly less than the repeatability of the measurement system and essentially means that capacitive effects have been removed from the result. The actual measurement aligned well with the 8 section multi flash measurements as predicted. The result can be seen in Fig 8. For comparison the single pulse measurements using a linear voltage ramp is also shown. For all the measurements the density of measurement points in the maximum power point region was set to be as close as possible to $5 \mathrm{~V}^{-1}$. 


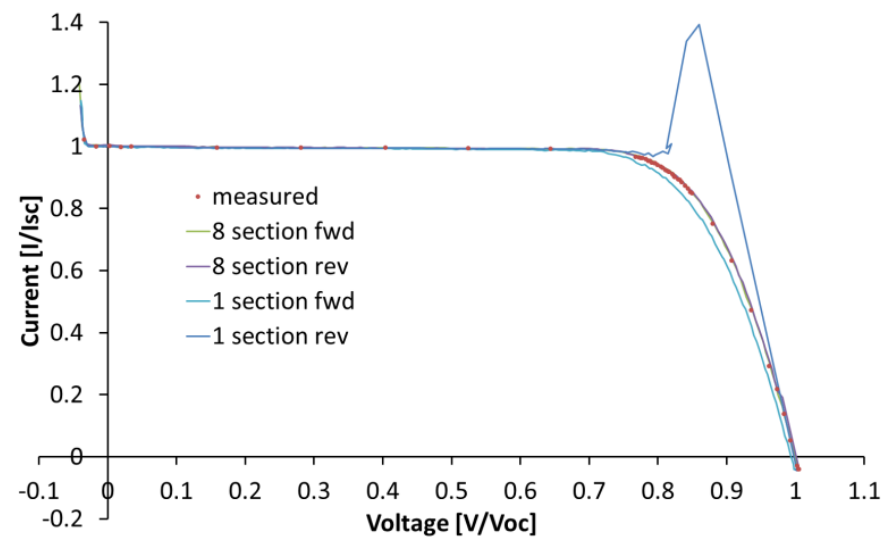

Fig 8. I-V curves measured using the new method compared to an 8 pulse multi section measurement and a single pulse linear voltage ramp measurement

\section{CONCLUSION}

It was demonstrated that it is possible to specifically tailor the voltage ramp used for performance measurement of high capacitance photovoltaic modules in order to significantly reduce the required measurement time, while maintaining high levels of accuracy. Using impedance measurements this can be done rapidly and automatically without the need for any extra illumination pulses. On a production line the ability to tailor the measurement for each individual module means the process should be robust and better able to cope with outlier modules. The $\mathrm{C}-\mathrm{V}$ characteristic and dark I-V of the modules are obtained as highly useful by-products of this method. As an example of the utility of the $\mathrm{C}-\mathrm{V}$ the minority carrier lifetime was extracted for an $n$ type module.

\section{REFERENCES}

[1] G. Friesen and H. Ossenbrink, "Capacitance effects in highefficiency cells," Solar Energy Mater. Solar Cells, vol. 48, pp. 77-83, NOV, 1997.

[2] P. R. Beljean, A. Lo, M. Despeisse, Y. Riesen, Y. Pelet, V. Fakhfouri, N. Wyrsch and C. Ballif, "I/V measurement of high capacitance cells with various methods," in 26th EU PVSEC, Hamburg, 2011, pp. 3275-3275-3278

[3] W. Keogh, A. Blakers and A. Cuevas, "Constant voltage I-V curve flash tester for solar cells," Solar Energy Mater. Solar Cells, vol. 81, pp. 183-196, FEB 6, 2004.

[4] Y. Hishikawa, Precise Performance Measurement of HighEfficiency Crystalline Silicon Solar Cells. NEW YORK; 345 E 47TH ST, NEW YORK, NY 10017 USA: IEEE, 2006

[5] R. A. Sinton, "A solution to the problem of accurate flashtesting of high-efficiency modules," in 21st EU PVSEC, Dresden, 2006, pp. 634-634-638

[6] A. Edler, M. Schlemmer, J. Ranzmeyer and R. Harney, "Understanding and overcoming the influence of capacitance effects on the measurement of high efficiency silicon solar cells," Proceedings of the 2nd International Conference on Crystalline Silicon Photovoltaics (Siliconpv 2012), vol. 27, pp. 267-272, 2012.
[7] C. Monokroussos, R. Gottschalg, A. N. Tiwari, G. Friesen, D. Chianese and S. Mau, The Effects of Solar Cell Capacitance on Calibration Accuracy when using a Flash Simulator. NEW YORK; 345 E 47TH ST, NEW YORK, NY 10017 USA: IEEE, 2006

[8] C. Monokroussos, D. Etienne, K. Morita, C. Dreier, U. Therhaag and W. Herrmann, "Accurate power measurements of high capacitance PV modules with short pulse simulators in a single flash," in 2012, pp. 3687-3687-3692

[9] A. Virtuani, G. Rigamonti, G. Friesen, D. Chianese and P. Beljean, "Fast and accurate methods for the performance testing of highly-efficient c-Si photovoltaic modules using a $10 \mathrm{~ms}$ single-pulse solar simulator and customized voltage profiles," Meas Sci Technol, vol. 23, pp. 115604, NOV, 2012.

[10] M. Herman, M. Jankovec and M. Topic, "Optimisation of the I-V measurement scan time through dynamic modelling of solar cells," IET Renew. Power Gener., vol. 7, pp. 63-70, JAN, 2013.

[11] M. Herman, M. Jankovec and M. Topic, "Optimal I-V Curve Scan Time of Solar Cells and Modules in Light of Irradiance Level," Int. J. Photoenergy, pp. 151452, 2012.

[12] I. Mora-Sero, Y. Luo, G. Garcia-Belmonte, J. Bisquert, D. Munoz, C. Voz, J. Puigdollers and R. Alcubilla, "Recombination rates in heterojunction silicon solar cells analyzed by impedance spectroscopy at forward bias and under illumination," Solar Energy Mater. Solar Cells, vol. 92, pp. 505-509, APR, 2008.

[13] D. Hinken, A. Milsted, R. Bock, B. Fischer, K. Bothe, M. Schuetze, J. Isenberg, A. Schulze and $M$. Wagner, "Determination of the Base-Dopant Concentration of LargeArea Crystalline Silicon Solar Cells," IEEE Trans. Electron Devices, vol. 57, pp. 2831-2837, NOV, 2010.

[14] S. M. (. Sze, Semiconductor Devices : Physics and Technology. New York: Wiley, 2001 